\title{
Lipid-based bio-fungicides for control of powdery mildew in cucurbits
}

\author{
Annette Ah Chee ${ }^{1}$, Maureen George ${ }^{1}$, Maryam Alavi ${ }^{2}$ and Kirstin Wurms ${ }^{1, *}$ \\ ${ }^{1}$ The New Zealand Institute for Plant \& Food Research Limited, Private Bag 3230, Hamilton \\ 3240, New Zealand \\ ${ }^{2}$ The New Zealand Institute for Plant \& Food Research Limited, Private Bag 92169, Auckland, \\ New Zealand \\ ${ }^{*}$ Corresponding author: kirstin.wurms@plantandfood.co.nz
}

\begin{abstract}
Powdery mildew (PM) infection of cucurbits is a major problem facing commercial New Zealand growers. Resistance to demethylation inhibitor fungicides is widespread so, there is a demand for new-generation bio-fungicides that can provide durable control alternatives in both conventional and organic systems. A wide range of milk products, plant and animal fats/oils, and natural plant elicitors were tested for their ability to control PM on squash and zucchini plants in a series of four glasshouse trials. The most promising product tested was anhydrous milk fat (AMF), in formulation with an emulsifier (Alanate $191^{\mathrm{mm}}$ or Panodan ${ }^{\circ}$ AL10), an antioxidant (Grindox 122 $2^{\text {in }}$ ) and/or other products (Synertrol Horti oil). These treatments were as effective as commercial fungicides in controlling PM, but there were significant issues with plant health. Future work will focus on reducing concentrations of the active ingredient to produce an effective formulation that is not detrimental to plant health. Soybean oil, coconut fat and olive oil formulations with Panodan ${ }^{\oplus}$ AL10 and Grindox $122^{\mathrm{m}}$ also gave effective PM control with minimal effect on plant health.
\end{abstract}

Keywords anhydrous milk fat, casein, coconut fat, cucurbit powdery mildew, milk, olive oil, soybean oil, whey

\section{INTRODUCTION}

Powdery mildew (PM) disease is characterised by fluffy white lesions on aerial plant tissues. It is caused by pathogens from the Erysiphales order and is responsible for significant yield losses globally in crops such as cucurbits, apples, roses, tomatoes, grapes and various cereals (Pasini et al. 1997; Glawe 2008). There are serious limitations with existing control methods, such as resistance to demethylation inhibitor fungicides (LopezRuiz et al. 2010; Colcol et al. 2012) and restrictions on the use of sulphur and copperbased fungicides in organic systems. These issues are driving the development of bio-fungicides (fungicides comprising biological control agents and/or natural products) with both eradicant and preventative activities that are suitable for both organic and conventional growers.

Milk products have been used informally as bio-fungicides for many years with varying success (Bettiol 1999; Ferrandino \& Smith 2007; Savocchia et al. 2011; Martins et al. 2016), but have not been commercialised, due to problems such as milk spoilage, handling difficulties, poor durability of control, and unwanted growth of non-target organisms. Milk is a nutritionally complex mixture and some of its components have antimicrobial activity, such as whey protein (Crisp et al. 2006; Bettiol et al. 2008) and fats (Horincar \& Bahrim 2017). Other components, e.g. the sugar lactose, act as a food source for some microbes such as sooty mould (Wikipedia 2017). The current study involved a series of glasshouse trials using Cucurbita maxima (squash) and/or

New Zealand Plant Protection 71: 262-271 (2018)

https://doi.org/10.30843/nzpp.2018.71.123 
Cucurbita pepo (zucchini plants) and had two objectives. The first was to test partially purified fractions of the major components of milk in order to assess their fungicidal activity against the cucurbit PM pathogen Sphaerotheca fuliginea and to avoid the problem of growth of non-target organisms. The second was to test various natural product active ingredients, including plant and animal lipids and elicitors of host resistance for their ability to control Sphaerotheca fuliginea, without adversely affecting leaf health.

\section{MATERIALS AND METHODS}

One variety of squash (Cucurbita maxima) 'Delica' and one of zucchini (Cucurbita pepo) 'Black Jack' were chosen for this study as they are known to be susceptible to PM. Plants were maintained in glasshouses with temperature ranging from $15^{\circ} \mathrm{C}$ (night) to $25^{\circ} \mathrm{C}$ (day) and a natural photo-period. One sticky trap $(20 \times 20 \mathrm{~cm})$ was suspended over plants on each glasshouse table to trap sap sucking insects, such as whiteflies, whose sugary exudates encourage the growth of sooty mould (caused by different Ascomycete fungi). Four trials were conducted and each was set out in a randomised block design (RBD) with one replicate plant/ treatment/block. Trials commenced when plants had eight or more true leaves. All flowers, fruit and secondary shoots were removed during the trials and the growing tips were cut back once the plants had 11 true leaves.

All plants in Trials 1-3, except for those in the un-inoculated control treatment, were artificially inoculated with $S$. fuliginea to ensure even infection across treatments. Sphaerotheca fuliginea is an obligate parasite so fungal colonies were maintained on dedicated inoculum squash plants. Leaves were harvested from these infected plants and the spores were lightly tapped off them over the adaxial surface of the first true leaf of each experimental plant. The remaining leaves on each plant were left to develop infection naturally. Artificial inoculation was considered unnecessary in Trial 4 because of the heavy inoculum load already present in the glasshouse.

The treatments were applied to all leaves at 7 -day intervals by spraying the adaxial surfaces to run-off using hand-held mister-bottles. Uninoculated and inoculated controls, where used, were sprayed with water. All treatments were prepared the day before application and stored overnight at $4^{\circ} \mathrm{C}$.

Severity of disease infection on true leaves 3 to 8 was assessed at the end of each trial using percent leaf area infection diagrams (Fig. 1) and a disease-rating scale (Table 1) described by Spencer (1977). These ratings were averaged for each plant and were converted to quantitative percent infection values by taking the mid-

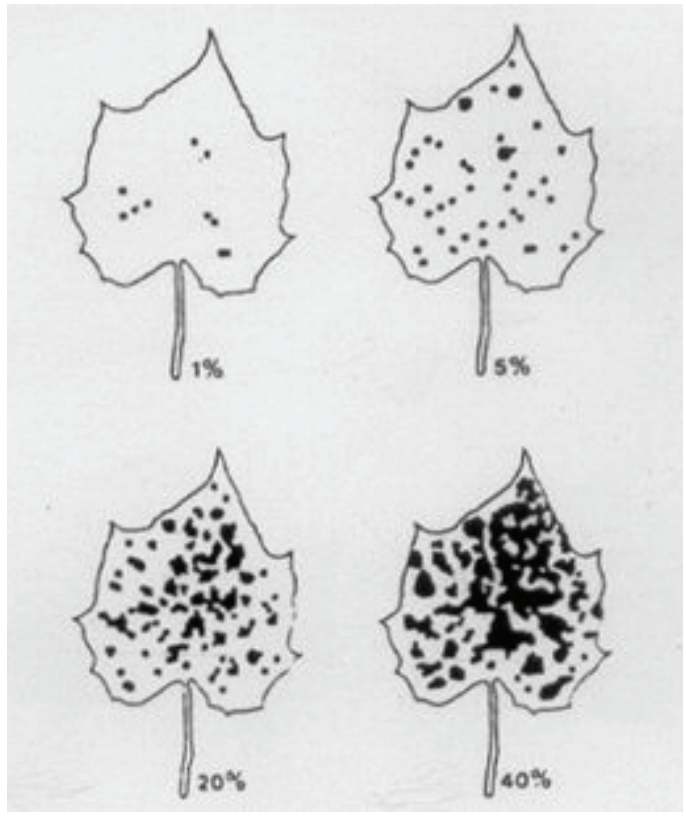

Figure 1 Powdery mildew percent leaf area infection diagrams from Spencer (1977).

Table 1 Powdery mildew leaf disease rating scale from Spencer (1977).

\begin{tabular}{cc}
\hline Rating & Leaf area (\%) infected \\
\hline 0 & no infection \\
1 & $0-1$ \\
2 & $2-5$ \\
3 & $6-20$ \\
4 & $21-40$ \\
5 & $>40$ \\
6 & 100 \\
\hline
\end{tabular}


point of the infection range corresponding to each severity score. Treatment differences were assessed using a RBD by analysis of variance (ANOVA), with means separation by Fisher's Least Significant Difference (LSD) $(\mathrm{P}<0.05)$, using Genstat 17th Edition.

At the same time as the disease assessment, qualitative assessments of leaf health were made using an arbitrary rating scale given in Table 2 . The qualitative assessments of leaf health were not statistically analysed.

\section{Trial 1 - whole milk and milk-protein fractions} This trial involved nine treatments of squash plants (Table 3). There were eight replicates per treatment. Four milk products were tested whole milk powder, crude whey protein, purified whey protein and purified casein protein (sodium caseinate). The first treatment application was
5 days prior to artificial inoculation with $S$. fuliginea and then weekly for a total period of 6 weeks.

Trial 2 - whole milk, milk protein, anhydrous milk fat (AMF) and chitosan

This trial consisted of ten treatments on squash plants and had eight replicates per treatment. This trial tested a different range of milk products than Trial 1 . The products tested were: colostrum (the first form of milk produced by mammals following birth), which contains more protein than milk; AMF; a moderately purified whey protein; purified casein protein; and the polysaccharide chitosan, which is a plant elicitor (Table 4). These treatments were compared with a commercial fungicide $\mathrm{Bravo}^{\circ}$. Un-inoculated and inoculated treatments had similar infection levels in Trial 1, so only an inoculated control was

Table 2 Arbitrary rating scale used to assess leaf health.

\begin{tabular}{cl}
\hline Rating & Leaf health \\
\hline A & Perfect condition - no abiotic or biotic blemishes \\
B & Small blemishes, e.g. chlorotic patches \\
C & Severe/advanced chlorosis, necrosis or leaf distortion \\
D & Leaf dead \\
\hline
\end{tabular}

Table 3 Composition of the milk product and other treatments used in Trial 1.

\begin{tabular}{|c|c|c|}
\hline $\begin{array}{c}\text { Treatment } \\
\text { (Trt) \# }\end{array}$ & Trt abbreviation & $\operatorname{Trt}^{1}$ details (ready-to-spray concentration) \\
\hline 1 & Uninoc-water & Un-inoculated control - water \\
\hline 2 & Inoc-water & Inoculated control - water \\
\hline 3 & Milk-15 & Whole milk powder $(15 \mathrm{~g} / \mathrm{L})$ \\
\hline 4 & Milk-30 & Whole milk powder $(30 \mathrm{~g} / \mathrm{L})$ \\
\hline 5 & $895-15$ & Purified whey - Alacen $895^{\mathrm{m \omega}}(15 \mathrm{~g} / \mathrm{L})$ \\
\hline 6 & $895-30$ & Purified whey - Alacen $895^{\mathrm{Tm}}(30 \mathrm{~g} / \mathrm{L})$ \\
\hline 7 & $621-30$ & Crude whey - Alaway $621^{\mathrm{mm}}(30 \mathrm{~g} / \mathrm{L})$ \\
\hline 8 & 191-15 & Sodium caseinate - Alanate $191^{\mathrm{mm}}(15 \mathrm{~g} / \mathrm{L})$ \\
\hline 9 & $191-30$ & Sodium caseinate - Alanate $191^{\mathrm{min}}(30 \mathrm{~g} / \mathrm{L})$ \\
\hline
\end{tabular}

${ }^{1}$ The milk products were supplied by New Zealand Milk Products Ltd. Alacen $895^{\text {mat }}$ contained $95 \%$ whey protein. Alaway $621^{m w}$ contained $13 \%$ whey protein and $75 \%$ milk sugar. There was only sufficient of this product to make up the $30 \mathrm{~g} / \mathrm{L}$ concentration. Alanate $191^{\mathrm{mw}}$ contained $93 \%$ casein protein. 
Table 4 Composition of the milk product and other treatments used in Trial 2.

\begin{tabular}{cll}
\hline $\begin{array}{c}\text { Treatment (Trt) } \\
\#\end{array}$ & Trt abbreviation & Trt $^{1}$ details (ready-to-spray concentration) \\
\hline 1 & Water & Inoculated water control \\
2 & Bravo & Bravo $^{\circledR}(3 \mathrm{~mL} / \mathrm{L})$ fungicide \\
3 & Colos-15 & Colostrum powder $(15 \mathrm{~g} / \mathrm{L})$ \\
4 & Colos-30 & Colostrum powder $(30 \mathrm{~g} / \mathrm{L})$ \\
5 & AMF-15 & Emulsified AMF $(15 \mathrm{~g} / \mathrm{L})$ \\
6 & AMF-30 & Emulsified AMF $(30 \mathrm{~g} / \mathrm{L})$ \\
7 & K-cas-15 & Potassium $(\mathrm{K})$-caseinate $(15 \mathrm{~g} / \mathrm{L})$ \\
8 & K-cas-30 & K-caseinate $(30 \mathrm{~g} / \mathrm{L})$ \\
9 & $312-30$ & Alacen $312^{\text {mix }}(30 \mathrm{~g} / \mathrm{L})$ \\
10 & Milk/Chit & Whole milk powder $(30 \mathrm{~g} / \mathrm{L})+$ chitosan $(20 \mathrm{~mL}$ \\
\hline
\end{tabular}

${ }^{1}$ The milk products supplied by New Zealand Milk Products Ltd were: colostrum powder; anhydrous milk fat (AMF), comprising 99.9\% solid milk fat, emulsified using 4 g/L Grindsted ${ }^{\mathrm{ww}}$ Mono-Di HV40 (Danisco Ltd, Braband, Denmark); potassium-caseinate; Alacen $312^{\mathrm{mw}}$, containing $80 \%$ whey protein; and whole milk powder. The stock of the elicitor, chitosan from shrimp shells (C-3646, Sigma, St Louis, MO, USA), was prepared by dissolving $600 \mathrm{mg}$ of chitosan in $125 \mathrm{~mL}$ of $25 \mathrm{mM}$ sodium acetate buffer, $\mathrm{pH}$ 5.5. Bravo fungicide came from Yates, Auckland, New Zealand, and was applied at concentrations recommended by the supplier.

used in Trial 2. As in Trial 1, the first treatment application was 5 days prior to artificial inoculation with $S$. fuliginea and then weekly for 6 weeks.

\section{Trial 3 - whole milk, milk fats and elicitors}

This trial involved eight replicates each of squash and zucchini plants. Nine treatments were applied (Table 5). Emulsified AMF, which had performed well in Trial 2, was tested both with and without an antioxidant (Grindox $\left.122^{\mathrm{im}}\right)$. Whole milk powder was tested on its own and also in combination with each of the plant elicitors: sodium salicylate (NaSA); yeast extract; almond oil; or a commercial inducer of host-plant resistance, Bion ${ }^{\star}$. A powdered cream product (Alaco ${ }^{\mathrm{Tx}}$ cream powder 55 ) was also tested. The fungicide control in this trial was the sulphur-based Kumulus ${ }^{\circledast}$ DF. In this trial, two spray applications were made 7 and 2 days before artificial inoculation with $S$. fuliginea and then weekly for a total of 4 weeks. Timing of the first treatment applications was different from the other trials because evidence from our research suggested that 7- and 2-day applications of elicitor prior to inoculation optimised the plant defence response (Tony Reglinski, Plant \& Food Research, unpublished data).

\section{Trial 4 - plant and animal lipids}

The final trial involved squash plants only. Fourteen treatments were tested (Table 6) with eight replicates per treatment. In the previous trials, AMF was the most promising milk product so in this trial its performance was compared with other milk fats (buttermilk and cream powder), and with other plant and animal fats and oils (Synertrol Horti oil, soybean oil, fish oil, coconut fat, olive oil). Kumulus ${ }^{\oplus}$ DF was the commercial fungicide control. Several 
Table 5 Composition of the milk product and other treatments used in Trial 3.

\begin{tabular}{|c|c|c|}
\hline $\begin{array}{l}\text { Treatment } \\
\text { (Trt) \# }\end{array}$ & Trt abbreviation & $\operatorname{Trt}^{1}$ details (ready-to-spray concentration) \\
\hline 1 & Kumulus & Kumulus ${ }^{\oplus}$ DF $(3 \mathrm{~g} / \mathrm{L})$ \\
\hline 2 & $\mathrm{AMF} / \mathrm{HV} 40$ & AMF (30 g/L)+Grindsted ${ }^{\mathrm{mm}}$ Mono-Di HV40 (4 g/L) \\
\hline 3 & AMF/HV40/122 & $\begin{array}{l}\text { AMF }(30 \mathrm{~g} / \mathrm{L})+\text { Grindsted }^{\mathrm{Tm}} \text { Mono-Di HV40 }(4 \mathrm{~g} / \mathrm{L})+\text { Grindox } 122 \\
(1 \mathrm{~g} / \mathrm{L})\end{array}$ \\
\hline 4 & Milk/NaSA & Whole milk powder $(30 \mathrm{~g} / \mathrm{L})+\mathrm{NaSA}(7.5 \mathrm{~mL}$ stock solution/L) \\
\hline 5 & Milk/Yeast & $\begin{array}{l}\text { Whole milk powder }(30 \mathrm{~g} / \mathrm{L})+\text { yeast extract }(20 \mathrm{~mL} \text { stock } \\
\text { solution/L) }\end{array}$ \\
\hline 6 & Milk/Bion & Whole milk powder $(30 \mathrm{~g} / \mathrm{L})+\operatorname{Bion}^{\oplus}(0.1 \mathrm{~g} / \mathrm{L})$ \\
\hline 7 & Milk/Almond & Whole milk powder $(30 \mathrm{~g} / \mathrm{L})+$ almond oil $(10 \mathrm{~mL}$ stock solution/L) \\
\hline 8 & Milk & Whole milk powder $(30 \mathrm{~g} / \mathrm{L})$ \\
\hline 9 & Cream 55 & Alaco $^{\text {tw }}$ cream powder $55(30 \mathrm{~g} / \mathrm{L})$ \\
\hline
\end{tabular}

${ }^{1}$ Kumulus $^{\oplus}$ DF (BSAF, Germany) is a sulphur-based fungicide and was applied at concentrations recommended by the supplier. The milk products were supplied by New Zealand Milk Products Ltd. Alaco ${ }^{\text {tw }}$ cream powder 55 is a spray-dried blend of cream and skim milk containing $55 \%$ milk fat. Grindox $122^{\mathrm{ma}}$ antioxidant (Danisco Ltd, Braband, Denmark) helps to prevent fatty acid chain breakdown. Elicitor stock solutions were prepared of sodium salicylate (NaSA, $200 \mathrm{mM}$ ), yeast extract ( $5 \mathrm{~g}$ of crude cell wall extract of Saccharomyces cereviseae (Brewer's yeast)/L water), and almond oil $(7.5 \% \mathrm{v} / \mathrm{v})$ in water. Bion ${ }^{\oplus}$ elicitor was obtained from Syngenta, NC, USA.

Table 6 Composition of the milk product and other treatments used in Trial 4.

\begin{tabular}{|c|c|c|}
\hline $\begin{array}{l}\text { Treatment } \\
\text { (Trt) \# }\end{array}$ & Trt abbreviation & $\operatorname{Trt}^{1}$ details (ready-to-spray concentration) \\
\hline 1 & Water & Water control \\
\hline 2 & Kumulus & Kumulus $^{\circledast}$ DF $(3 \mathrm{~g} / \mathrm{L})$ \\
\hline 3 & $\mathrm{AMF} / 191 / 122$ & $\operatorname{AMF}(30 \mathrm{~g} / \mathrm{L})+$ Alanate $191^{\mathrm{TM}}(15 \mathrm{~g} / \mathrm{L})+$ Grindox $122^{\mathrm{ms}}(1 \mathrm{~g} / \mathrm{L})$ \\
\hline 4 & AMF/DATEM/122 & $\operatorname{AMF}(30 \mathrm{~g} / \mathrm{L})+\mathrm{DATEM}(8 \mathrm{~g} / \mathrm{L})+$ Grindox $122^{\mathrm{max}}(1 \mathrm{~g} / \mathrm{L})$ \\
\hline 5 & Syn & Synertrol Horti oil (5 mL/L) \\
\hline 6 & Fish & Fish oil $(20 \mathrm{~mL} / \mathrm{L})$ \\
\hline 7 & SBO/DATEM/122 & Soybean oil $(20 \mathrm{~mL} / \mathrm{L})+\operatorname{DATEM}(8 \mathrm{~g} / \mathrm{L})+$ Grindox $122^{\mathrm{mm}}(1 \mathrm{~g} / \mathrm{L})$ \\
\hline 8 & Coco/DATEM/122 & Coconut fat $(20 \mathrm{~g} / \mathrm{L})+$ DATEM $(8 \mathrm{~g} / \mathrm{L})+$ Grindox $122^{\mathrm{mix}}(1 \mathrm{~g} / \mathrm{L})$ \\
\hline 9 & Oli/DATEM/122 & Olive oil $(20 \mathrm{~mL} / \mathrm{L})+$ DATEM $(8 \mathrm{~g} / \mathrm{L})+$ Grindox $122^{\mathrm{mw}}(1 \mathrm{~g} / \mathrm{L})$ \\
\hline 10 & AMF/DATEM/Fish & $\operatorname{AMF}(30 \mathrm{~g} / \mathrm{L})+\mathrm{DATEM}(8 \mathrm{~g} / \mathrm{L})+$ fish oil $(20 \mathrm{~mL} / \mathrm{L})$ \\
\hline 11 & AMF/DATEM/Syn & AMF (30 g/L)+DATEM (8 g/L)+ Synertrol Horti oil (5 mL/L) \\
\hline 12 & AMF/191/122/Natamax & $\begin{array}{l}\text { AMF }(30 \mathrm{~g} / \mathrm{L})+\text { Alanate } 191^{\mathrm{Tm}}(15 \mathrm{~g} / \mathrm{L})+\text { Grindox } 122^{\mathrm{mm}}(1 \mathrm{~g} / \mathrm{L}) \\
+\operatorname{Natamax}^{\mathrm{mm}}(20 \mathrm{mg} / \mathrm{L})\end{array}$ \\
\hline 13 & Buttermilk & Buttermilk powder $(30 \mathrm{~g} / \mathrm{L})$ \\
\hline 14 & Cream 70 & Alaco $70^{\text {tw }}$ cream powder $(30 \mathrm{~g} / \mathrm{L})$ \\
\hline
\end{tabular}

${ }^{1}$ The milk products were supplied by New Zealand Milk Products Ltd. Buttermilk powder comprised $8 \%$ fat $(\mathrm{w} / \mathrm{w})$. Alaco $70^{\text {max }}$ cream powder is a spray-dried blend of cream and skim milk containing $70 \%$ milk fat. Synertrol Horti Oil is a canola-oil-based spray adjuvant. Fish oil (Bio-Sea ${ }^{\text {mit }}$ ), produced from the species Hoplostethus atlanticus (orange roughy), was obtained from SeaLord Group Ltd, Nelson, NZ. Soybean oil, coconut fat, and olive oil were purchased from a supermarket. Natamax ${ }^{\text {mm }}$ (Danisco Ltd, Braband, Denmark) is a food preservative containing the natural anti-fungal compound natamycin, produced by the bacterium Streptomyces natalensis. Panodan ${ }^{\circ}$ AL10 (DuPont) is a diacetyl tartaric acid ester of mono- and diglycerides (DATEM). 
treatments involved formulating AMF using two different emulsifiers (Panodan AL10 or Alanate $191^{\mathrm{Tw}}$ ) instead of Mono-Di HV40 used in Trial 3 because HV40 caused problems with blockage of spray nozzles. Alanate $191^{\mathrm{TM}}$ is a type of milk protein (sodium caseinate), but was used in this trial as an emulsifier. Treatment applications were made weekly for a total period of 6 weeks.

\section{RESULTS}

\section{Trial 1 - whole milk and protein fractions}

The 191-30 and Milk-30 treatments were the most effective at reducing PM, followed by Milk15, 621-30 and 191-15 (Fig. 2). Inoculated and un-inoculated water-sprayed control plants had the highest severity of infection and were not significantly different due to the heavy inoculum load present in the glasshouse from infected plants.

The treatments that included Alanate 191 had the best median leaf health rating of $\mathrm{B} / \mathrm{C}$ versus Alaway 621, which had a rating of C/D. All other treatments (including the water control) had a median health rating of $\mathrm{C}$. There was no sooty mould development in any of the treatments.
Trial 2 - whole milk, protein and anhydrous milk fat (AMF)

The AMF treatments were significantly better at controlling PM any other treatment (Fig. 3). Milk/Chit and Colos-30 were the next most effective treatments. Bravo ${ }^{\oplus}$ fungicide provided significantly less control than five of the milk product treatments.

The Milk/Chit treatment had the best median leaf health rating of $B$ and the water treatment the worst rating of $\mathrm{D}$. All other treatments had a C/D rating. There was no sooty mould development in any of the treatments.

\section{Trial 3 - whole milk, protein and AMF}

Most of the squash plants treated with Milk/ Bion died, so only the results for the other eight treatments are presented. Results for all nine treatments are presented for zucchini plants. The population of whiteflies built up in the glasshouse during Trial 3 despite the presence of sticky traps and sooty mould growth was observed on plants treated with milk.

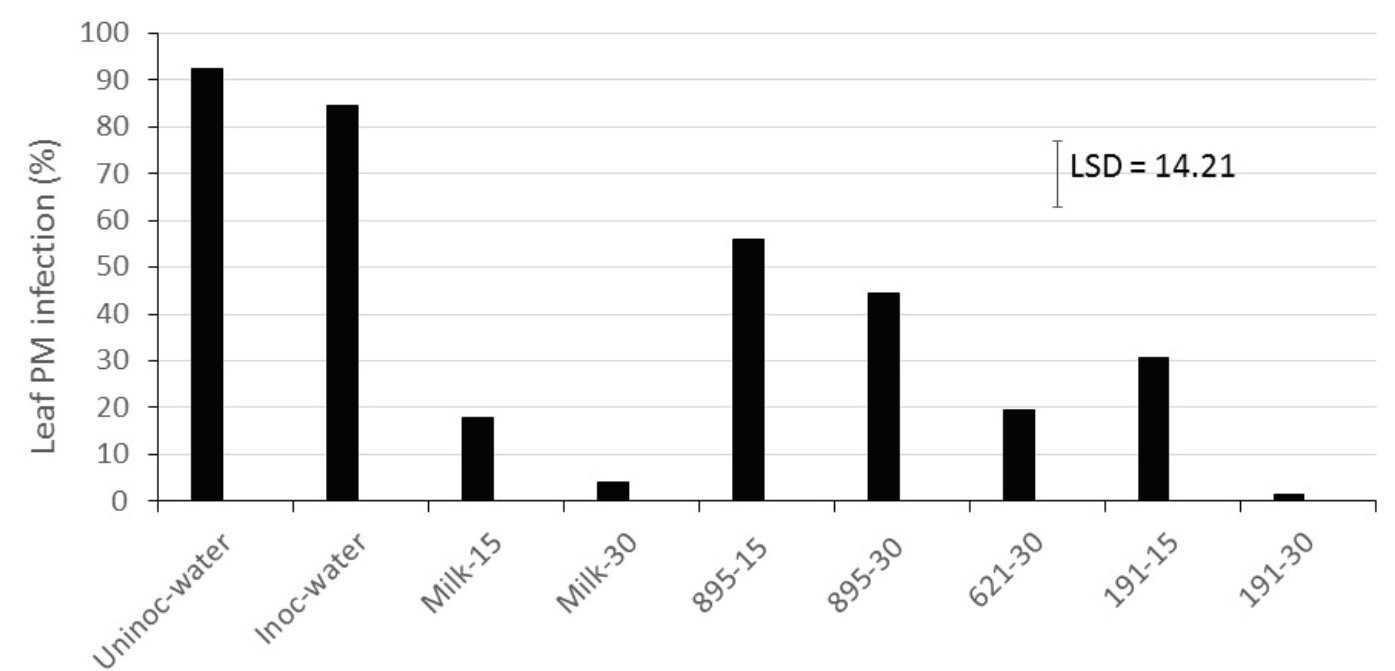

Figure 2 Trial 1 - the effect of milk product treatments on powdery mildew (PM) disease severity on 'Delica' squash leaves after six applications, applied weekly. The milk products supplied by New Zealand Milk Products Ltd are detailed in Table 3. There were eight single replicate plants per treatment, arranged in a completely randomised block design. Data were analysed by analysis of variance (ANOVA), with means separation by Fisher's Least Significant Difference (LSD) $(\mathrm{P}<0.05)$. 


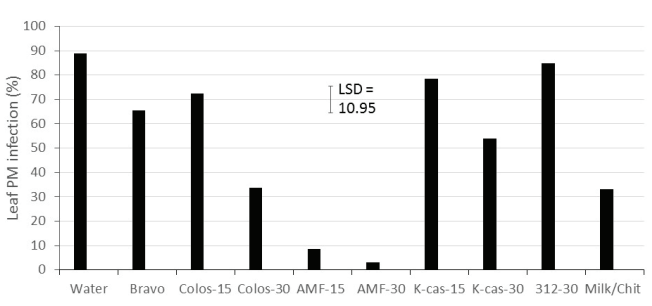

Figure 3 Trial 2 - the effect of milk product treatments on powdery mildew (PM) on 'Delica' squash leaves after six applications, applied weekly. Treatments are detailed in Table 4. There were eight single replicates per treatment, arranged in a randomised block design. Data were analysed by ANOVA, with means separation by LSD $(\mathrm{P}<0.05)$.

\section{Squash}

The most effective treatments were Kumulus, AMF/HV40 and AMF/HV40/122 (Fig. 4). The next best treatments were Milk/Almond and Cream 55.

The Kumulus, AMF/HV40/122, AMF/HV40 and Milk/Almond treatments had the best median leaf health rating of $B$. All other treatments had a median health rating of B/C. Sooty mould was abundant in this trial in all treatments except for the Kumulus and the AMF treatments (data not shown). Sooty mould incidence was most severe in the Milk/Yeast, Milk and Cream 55 treatments (data not shown).

\section{Zucchini}

As was the case with squash plants in this trial, the Kumulus and AMF treatments provided the most effective PM disease control on zucchini plants (Fig. 5).

Median leaf health ratings were: A/B for the AMF/HV40, AMF/HV40/122, Milk/NaSA, and Milk/Yeast treatments; B for Kumulus, Milk/ Almond, Milk, and Cream 55 treatments; and B/C for Milk/Bion treatment. Sooty mould was most severe in the Milk/Yeast, Milk and Cream 55 treatments, but was absent in the Kumulus ${ }^{\oplus}$, $\mathrm{AMF} / \mathrm{HV} 40$, and AMF/HV40/122 treatments (data not presented).

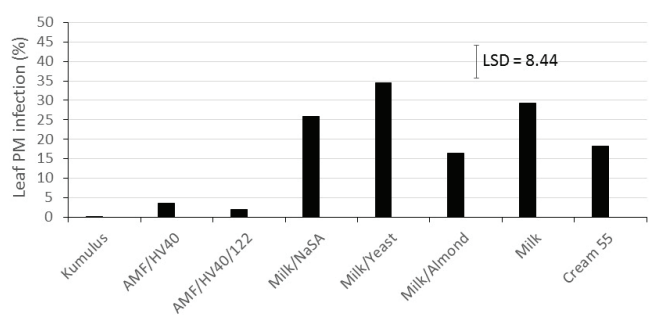

Figure 4 Trial 3 - the effect of milk product treatments on powdery mildew (PM) on 'Delica' squash leaves after four applications, applied weekly. Treatments are detailed in Table 5. There were eight replicates per treatment, in a randomised block design. Data were analysed by ANOVA, with means separation by LSD $(\mathrm{P}<0.05)$.

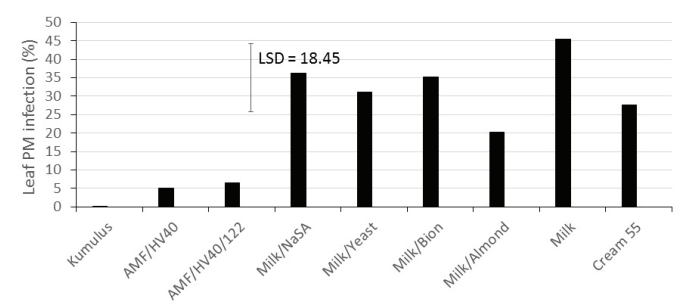

Figure 5 Trial 3 - the effect of milk product treatments on powdery mildew (PM) on 'Black Jack' zucchini leaves after four applications, applied weekly. Treatment codes are the same as in Figure 4, with the addition of the $30 \mathrm{~g} / \mathrm{L}$ whole milk $+0.1 \mathrm{~g} / \mathrm{L}$ Bion $^{\circledast}$ treatment (Milk/Bion). There were eight replicates per treatment, in a randomised block design. Data were analysed by ANOVA, with means separation by LSD $(\mathrm{P}<0.05)$.

\section{Trial 4 - plant and animal lipids}

AMF/DATEM/122 and SBO/DATEM/122 completely eliminated all PM disease, even in the presence of high disease pressure as shown in the water control, whilst Kumulus, Fish, Coco/ DATEM/122, Oli/DATEM/122, AMF/DATEM/ Fish and AMF/DATEM/Syn treatments also reduced PM infection to less than $5 \%$ of the leaf 
surface area (Fig. 6). Buttermilk and Cream 70 were not as effective as AMF, and disease control was better when DATEM rather than 191 was used as an emulsifier (Fig. 6). A comparison of the AMF/191/122 and AMF/191/122/Nat treatments showed that addition of Natamax did not improve disease control (Fig. 6).

The AMF/DATEM/122, Fish, AMF/DATEM/ Fish, AMF/DATEM/Syn, SBO/DATEM/122, Coco/DATEM/122 and Oli/DATEM/122 treatments were all effective in controlling PM. However, median leaf health ratings (C or D) were lower for AMF/DATEM/122, Fish, AMF/ DATEM/Fish, AMF/DATEM/Syn than for the SBO/DATEM/122, Coco/DATEM/122 and Oli/DATEM/122 (median health rating of $\mathrm{B}$ ). Whiteflies were present in the glasshouse during Trial 4 but sooty mould did not grow on any of the plants sprayed with AMF, Fish, SBO, Coco or Oli lipid formulations.

\section{DISCUSSION}

AMF was consistently the most effective of all the milk fractions tested for control of PM, and was not associated with growth of non-target organisms such as sooty mould or diminished efficacy over time, but did reduce the health rating on leaves. Of the various plant oil formulations tested, SBO was the most efficacious for PM disease control and did not adversely affect leaf health.

Treatments containing whole milk powder and whey proteins gave variable disease control depending on the concentration $(\mathrm{g} / \mathrm{L})$ of the active ingredient, purity of the product, and the nature of co-ingredients, and were associated with sooty mould growth in the presence of heavy whitefly populations. Savocchia et al. (2011) also observed that PM disease control efficacy of whole milk and whey protein was inconsistent and diminished over the course of two seasons' trial work on field-grown grapes. They concluded that these products were most suited to use on grape cultivars that were less susceptible to PM such as 'Cabernet Sauvignon' and 'Shiraz' and was best suited to conditions of low disease pressure.

In contrast to the performance of whole milk and protein fractions, AMF was the most fungitoxic milk component tested, with efficacy matching or exceeding that of commercial fungicides (Bravo, and Kumulus), sooty mould

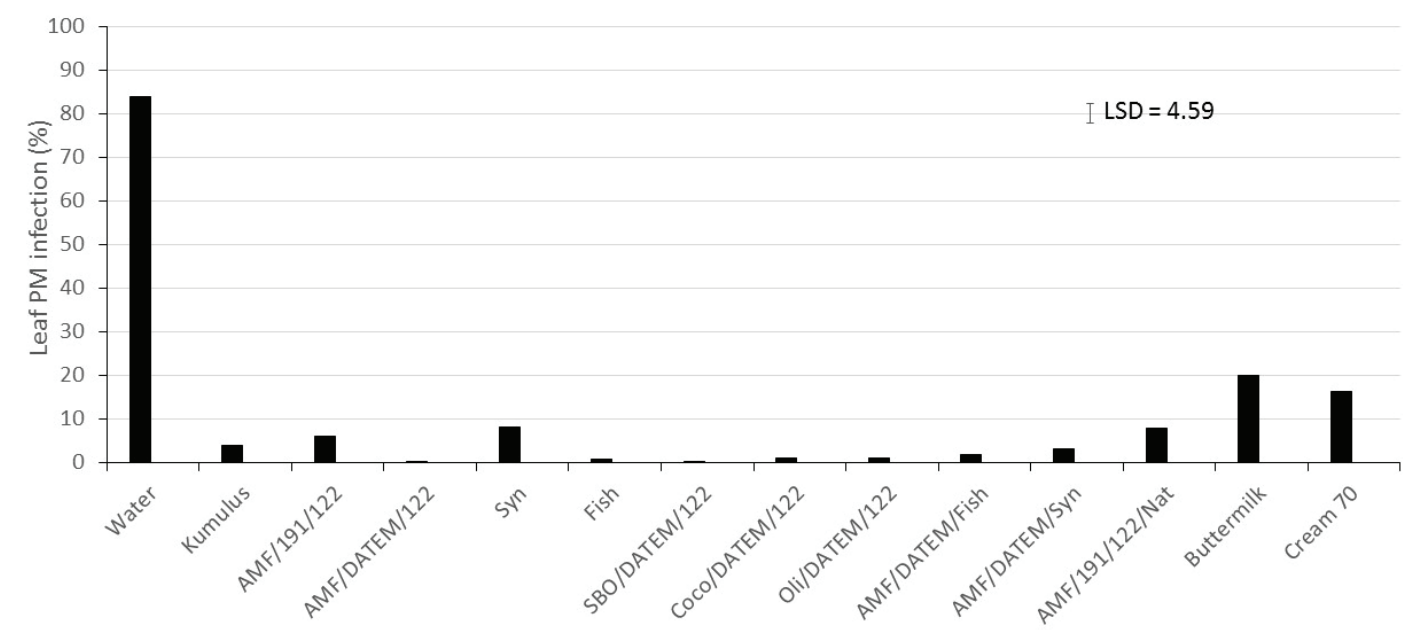

Figure 6 Trial 4 - the effect of plant and animal lipid spray treatments on powdery mildew (PM) severity on 'Delica' squash leaves after six applications, applied weekly. The treatment codes are given in Table 6. There were eight replicates per treatment, in a randomised block design. Data were analysed by ANOVA, with means separation by LSD $(\mathrm{P}<0.05)$. 
growth did not occur, and disease control was consistent even under the heavy inoculum loads present in all trials as indicated by $80-90 \%$ PM infection on leaves in the water treated control plants. When the different milk fat treatments in Trial 4 were ranked in order from greatest to least disease control, results showed that efficacy of disease control correlated positively with the percentage fat content, i.e. AMF (99.9\% fat) > Cream 70 (70\% fat) > Buttermilk (8\% fat) (Fig. $6)$.

However, the AMF treatments were associated with decreased plant health, and in general the plant lipids (soybean, olive oil and coconut fat) were equally effective in controlling PM, especially SBO, without any adverse effects on plant health (Fig. 6). The trade-off between the antimicrobial activity of fatty acids and phytotoxicity has been well documented (Takahashi et al. 2001; Gallardo-Williams et al. 2002; Fukuda et al. 2004; Lederer et al. 2004; Coleman \& Penner 2006). Finding an equilibrium between efficacy and plant health is critical to the success of any lipidbased bio-fungicide. Further work to address this issue for AMF could include reducing the concentration of AMF and evaluating the performance of alternative co-ingredients in the emulsion. For instance, use of DATEM emulsifier with AMF resulted in better PM disease control than either HV40 or Alanate 191 (Figs 4-6) and also overcame undesirable characteristics of the latter two emulsifiers, namely sprayer blockage and poor solubilisation, respectively. Choice of emulsifier and antioxidant is explored further in the following paper by Wurms \& Ah Chee (2018). Our findings also showed that addition of a range of plant elicitors to induce plant defences did not improve control efficacy of the milk treatments (Fig. 3). One reason for the failure of chitosan might be that we used a much lower concentration of the active ingredient $(0.096$ $\mathrm{g} / \mathrm{L})$ than the recommended field rate $(1.440$ $\mathrm{g} / \mathrm{L}$ ) of the commercial product, ArmourZen ${ }^{\circ}$ (Reglinski et al. 2010), because ArmourZen was not available at the time when this experiment was carried out. Formulation of AMF with other fats/oils such as fish oil, Synertrol oil, or addition of the preservative Natamax did not significantly improve control or leaf health (Fig. 6).

There was a significant difference between the level of protection provided by the registered fungicides, Kumulus and Bravo. The PM strain used in the trials was isolated from a glasshouse in Whangarei where Bravo had been used extensively, so it is possible that the fungus had developed some degree of fungicide resistance. This can occur in any situation where there is extensive use of any one fungicidal product, but it is anticipated that the development of biofungicides that offer multiple modes of action may slow the onset of resistance development.

This work has identified some extremely positive potential bio-fungicide candidates, particularly AMF and SBO emulsions, and future research should include optimisation of the AMF formulation, and testing of the most promising lipid based bio-fungicides in the field and against other horticulturally-important fungal pathogens. Commercial development of such fungicides will provide more environmentally benign and sustainable control options for growers.

\section{ACKNOWLEDGEMENTS}

Special thanks to Nicole Shukker, former employee of NZ Milk Products Ltd (now Fonterra) for her drive and enthusiasm for this project and to NZ Milk Products Ltd for funding the research. We are very grateful to Mike Spiers and Dr Tony Reglinski for their editorial comments.

\section{REFERENCES}

Bettiol W 1999. Effectiveness of cow's milk against zucchini squash powdery mildew (Sphaerotheca fuliginea) in greenhouse conditions. Crop Protection 18: 489-492.

Bettiol W, Silva HSA, Reis RC 2008. Effectiveness of whey against zucchini squash and cucumber powdery mildew. Scientia Horticulturae 117: 82-84.

Colcol JF, Rallos LE, Baudoin AB 2012. Sensitivity of Erysiphe necator to demethylation inhibitor fungicides in Virginia. Plant Disease 96: 111-116. 
Coleman R, Penner D 2006. Desiccant activity of short chain fatty acids. Weed Technology 20: 410-415.

Crisp P, Wicks TJ, Troup G, Scott ES 2006. Mode of action of milk and whey in the control of grapevine powdery mildew. Australasian Plant Pathology 35: 487-493.

Ferrandino FJ, Smith VL 2007. The effect of milkbased foliar sprays on yield components of field pumpkins with powdery mildew. Crop Protection 26: 657-663.

Fukuda M, Tsujino Y, Fujimori T, Wakabayashi K, Boger P 2004. Phytotoxic activity of middlechain fatty acids I: effects on cell constituents. Pesticide Biochemistry and Physiology 80: 143-150.

Gallardo-Williams MT, Geiger CL, Pidala JA, Martin DF 2002. Essential fatty acids and phenolic acids from extracts and leachates of southern cattail (Typha domingensis P.). Phytochemistry 59: 305-308.

Glawe DA 2008. The powdery mildews: A review of the world's most familiar (yet poorly known) plant pathogens. In: Annual Review of Phytopathology. Annual Reviews, Palo Alto. Pp. 27-51.

Horincar G, Bahrim G 2017. The antimicrobial properties of enzymatic hydrolysates of goat milk fat. Annals of the University Dunarea De Jos of Galati, Fascicle Vi-Food Technology 41: 30-40.

Lederer B, Fujimori T, Tsujino Y, Wakabayashi K, Boger P 2004. Phytotoxic activity of middle-chain fatty acids II: peroxidation and membrane effects. Pesticide Biochemistry and Physiology 80: 151-156.

Lopez-Ruiz FJ, Perez-Garcia A, FernandezOrtuno D, Romero D, Garcia E, de Vicente A, Brown JKM, Tores JA 2010. Sensitivities to DMI fungicides in populations of Podosphaera fusca in south central Spain. Pest Management Science 66: 801-808.

Martins SJ, Medeiros FHV, Andrade RC, Nunez AMP, Souza B, Moino A, Filgueiras CC 2016. Dual role of milk on aphid and powdery mildew control in kale. Scientia Horticulturae 203: 126-130.
Pasini C, Daquila F, Curir P, Gullino ML 1997. Effectiveness of antifungal compounds against rose powdery mildew (Sphaerotheca pannosa var. rosae) in glasshouses. Crop Protection 16: 251-256.

Reglinski T, Elmer PAG, Taylor JT, Wood PN, Hoyte SM 2010. Inhibition of Botrytis cinerea growth and suppression of botrytis bunch rot in grapes using chitosan. Plant Pathology 59: 882-890.

Savocchia S, Mandel R, Crisp P, Scott ES 2011. Evaluation of 'alternative' materials to sulfur and synthetic fungicides for control of grapevine powdery mildew in a warm climate region of Australia. Australasian Plant Pathology 40: 20-27.

Spencer DM 1977. Standardised methods for the evaluation of fungicides to control cucumber powdery mildew. In: McFarlane NR ed Crop Protection Agents - Their Biological Evaluation. Academic Press, London. Pp. 455-464.

Takahashi H, Ohki A, Kanzaki M, Tanaka A, Sato Y, Matthes B, Boger P, Wakabayashi K 2001. Very-long-chain fatty acid biosynthesis is inhibited by cafenstrole, N,N-diethyl3-mesitylsulfonyl-1H-1,2,4-triazole-1carboxamide and its analogs. Zeitschrift Fur Naturforschung C-a Journal of Biosciences 56: 781-786.

Wikipedia 2017. Sooty mold. https:// en.wikipedia.org/wiki/Sooty_mold (accessed 4 May 2018).

Wurms K, Ah Chee 2018. Product formulation is critical to the success of lipid-based biofungicides. New Zealand Plant Protection 71: 272-284. 